\title{
Historia
}

\section{La mujer ginecóloga y partera (Notas históricas)}

\author{
Fernando Sánchez-Torres*
}

Según Ghalioungui, en el Egipto faraónico se admitían mujeres en la profesión médica para desempeñar el oficio de comadronas (1). Igual cosa ocurría entre los hebreos; las matronas usaban ya el espéculo vaginal y practicaban la versión cefálica en caso de presentación de pelvis (2). En la antigua Grecia las mujeres también ejercían abiertamente la obstetricia; en cambio, la ginecología tenían que desempeñarla de manera clandestina (3). En Roma, a principios de nuestra era, ejercían dos clases de mujeres: las obstetrices, o comadronas, que atendían sólo casos sencillos y que apelaban a los médicos cuando se consideraban incompetentes para actuar; y las feminae medicae, que se anunciaban como expertas en enfermedades de la mujer (4).

El hombre aparece de comadrón por primera vez en el siglo VII de la era cristiana, personificado en Pablo de Egina, quien ejerció en Egipto y Asia Menor. Como cosa curiosa, recomendaba que el parto en las obesas se atendiera colocando a la mujer sobre su propio abdomen, con las piernas levantadas hacia atrás.

En la América prehispánica la mujer también desempeñó un papel destacado en asuntos obstétricos. Así, entre los mayas y los aztecas existían parteras expertas, pues practicaban versiones y embriotomías. Se llamaban tlamatqui ticitl, y a sus ayudantas tepalehuiam $(6,7)$. En cambio, entre los aborígenes que habitaban el territorio de lo que hoy es Colombia, Venezuela y Ecuador (8-10) no se acostumbraba el parto acompañado, sino solitario, como lo fue en las épocas más remotas de la humanidad. En el Alto Perú, es decir, el territorio que se reparten actualmente el Perú y Bolivia, el parto era asistido por comadres, según lo refiere J.M. Belcázar (11). Las parturientas daban a luz boca abajo, en "cuatro patas", apoyadas las manos y rodillas en el suelo; la comadre recibía la criatura por detrás. No obstante ésta referencia, Francisco J. De Urioste, citando al Inca Garcilaso de la Vega, registra que la mujer incaica paría sin parteras y que nunca las hubo (12). Si alguna mujer llegaba a desempeñar este oficio, era tenida como hechicera. Si nos atenemos a documentos incaicos de la época precolombina, como algunas piezas de alfarería (huacos), debemos aceptar que el parto era asistido por mujeres. Las aborígenes araucanas, en el extremo sur del Continente, daban a luz solas (13). Más tarde, sin saberse desde cuando, las parturientas de Tierra del Fuego fueron auxiliadas por las mujeres más ancianas de la localidad, o por sus propias madres. A estas

* Profesor Titular (Emérito y Honorario) de la Universidad Nacional de Colombia. Miembro Fundador de la Sociedad Colombiana de Historia de la Medicina. ayudantas se les llamaba cutoandundomo, que quería decir "mujer que se compadece de la amiga".

En Europa, promediando el siglo XVI, el arte de los partos estaba en manos de comadronas. Recordemos que sólo fue hasta el siglo XVII cuando se rompe ese matriarcado, exactamente en el famoso Hôtel Dieu, de París, al autorizar a los cirujanos la atención de los partos, incluyendo los normales. Era costumbre que el cirujano fuera llamado únicamente cuando se hacía inevitable extraer el feto a pedazos. En España, un médico natural de Palma, llamado Damián Carbón, escribió una obra titulada Libro del arte de las comadres o madrinas y del regimiento de las preñadas y de los niños, aparecido en 1541. Según el autor, la razón que lo movió a escribirlo estuvo sustentada en que "las preñadas y paridas, en sus necesidades y para las criaturas, a las comadres antes que a los médicos piden consejo, y ellas poco instruidas en su arte, no saben buenamente qué hacer, y así caen en errores" (14). Según Usandizaga, el oficio de comadrona no estaba reconocido legalmente en aquellas calendas, pero tenía importancia social. Damián en su libro fija las condiciones que debía reunir la comadrona para ser buena y eficiente. Veámoslas: experta, ingeniosa, bien moderada, honrada y casta para dar buenos consejos, tener temor de Dios y ser devota de la Virgen María (15). Sin duda, esa suma de virtudes que se exigía a la comadrona era rezago de los tiempos de Sorano de Efeso, el más famoso ginecólogo y obstetra de la Antigüedad Clásica. En efecto, para él las parteras debían ser, entre otras cosas, ilustradas, con buena memoria, robustas, de manos largas y uñas cortas, disciplinadas, discretas, poco amantes del dinero (16).

En Francia, a principios del siglo XVII, Luisa Bourgeois propone la inducción del parto prematuro para solucionar el problema de la estrechez pélvica. Esta partera fue muy famosa en su país; a ella se debe también la descripción semiológica para el diagnóstico de la presentación de cara, al igual que la importancia del diagnóstico oportuno del prolapso del cordón umbilical (17). En Alemania, en 1690, otra famosa partera, Justina Sigmundin, edita un libro destinado a sus colegas. En él llama la atención sobre la importancia de identificar el occipucio en las presentaciones cefálicas (18). Tanto la Bourgeois como la Sigmundin llegaron a ejercer su oficio en la misma corte. Pero, indudablemente, la mujer más famosa en el ejercicio obstétrico vivió en el siglo XIX. Llegó a ser la directora de la Maternidad de París y escribió un Tratado de Obstetricia, respaldado en una experiencia de 40.000 partos. Hasta no hace muchos años, cuando todavía se enseñaba la operatoria obstétrica vaginal, se recordaba la maniobra de Madame Lachapelle para introducir la segunda rama del fórceps, y también la 


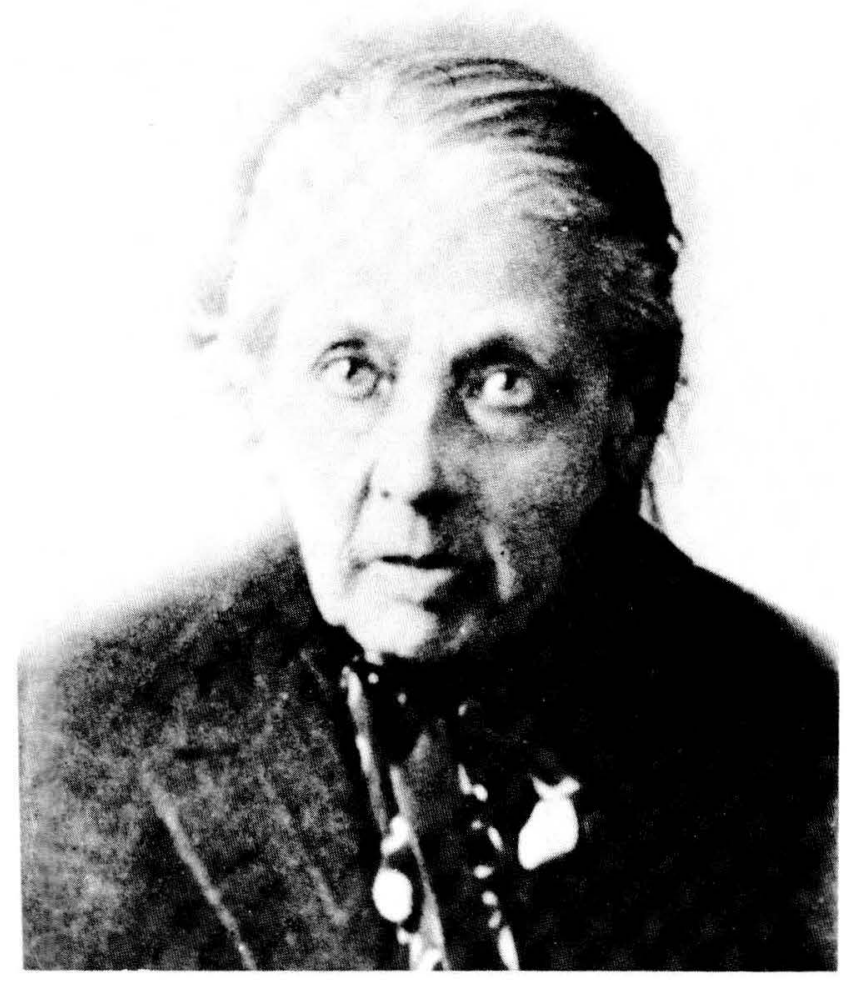

Doctora Ana Galvis Hotz

Natural de Bogotá, fue la primera médica colombiana y también la primera especialista en ginecología.

maniobra de mutación de una presentación de frente a una de cara, ideada por ella (19).

Entre nosotros, la mujer comienza a hacer presencia obstétrica luego de la llegada de los conquistadores españoles, pues fueron éstos quienes impusieron la costumbre de que los partos fueran asistidos por las "comadres sabias" (20). Sin embargo, pocas, o mejor ninguna referencia tenemos de lo que fueron sus primeras intervenciones, pero podemos imaginarlas si las asociamos con el libro que para ellas escribiera el citado Damián Carbón. Sólo encontramos mención de una tal Juana García. En efecto, refiere el cronista Juan de Castellanos que existía en Santafé un hombre casado con mujer moza y hermosa. En ausencia de aquél, como que había viajado a Castilla, "no quiso malograr su hermosura, sino gozar de ella. Descuidóse y hizo una barriga, pensando poderla despedir con tiempo; pero antes del parto le tocó a la puerta la nueva de la llegada de la flota a la ciudad de Cartagena, con lo cual la pobre señora se alborotó y hizo sus diligencias para abortar la criatura, y ninguna le aprovechó. Procuró tratar su negocio con Juana García, su madre, digo su comadre (...)" (21).

Una partera que tuvo renombre en Santafé a finales del siglo XVIII fue la comadre Melchora, quien vivía en la Calle de Las Véjares. Según Pedro María Ibáñez, una vez dueña de numerosa clientela ensanchó su radio de acción y se hizo curandera (22).
En un informe de José Celestino Mutis, fechado 3 de junio de 1801, sobre el estado de la medicina en el Nuevo Reino, anotaba el sabio gaditano: "Más urgente ha sido en los tiempos anteriores la necesidad de parteras instruidas. Destinadas al oficio por herencia; acreditadas por su virtud y honestidad; pero incapaces de auxiliar los partos trabajosos y difíciles, han contribuido a mantener el capricho de resistirse las parturientas a los auxilios de la cirugía (...)" (23).

En la tercera década del siglo XIX, por primera vez en nuestro país fueron habilitadas por la Facultad de Medicina para ejercer la profesión de parteras las comadres Juana Solórzano, Manuela Rodríguez e Isabel Cortés. Esa autorización era realmente exigua pues su radio de acción se reducía a recibir la criatura y cortar el cordón umbilical (24). Iguales funciones desempeñaban, en los inicios de la época republicana, algunas mujeres de la alta sociedad, que, motu proprio,resolvían hacer las veces de parteras para socorrer a las mujeres de su misma clase. Por el relato que el general Francisco de Paula Santander hiciera de sus actos realizados el día 28 de septiembre de 1824, fecha cuando se conspiró contra la vida del Libertador Bolívar, sabemos que su hermana Josefa de Briceño dio a luz una de sus hijas, asistida por las señoras esposas de los doctores Casimiro Calero y Casimiro Joaquín Suárez (25).

Digna de mención es Juana Quevedo, hija del doctor José Ignacio Quevedo Amaya, que como es sabido fue quien, en 1844, practicó la primera operación cesárea en Colombia, en mujer viva. Para entonces la familia Quevedo vivía en Medellín, y Juana, enamorada de la profesión de su padre, se aficionó a ella en tal forma que se decidió a ejercerla sin haber hecho estudios formales. Incursionó con buen éxito, pues, al decir de un descendiente suyo, "llegó a tener tanta clientela como su padre y su hermano". La obstetricia fue su fuerte (25).

Promediando la segunda mitad del siglo XIX, la ginecología y la obstetricia apenas comenzaban a esbozarse como especialidades. Al respecto decía Pedro María Ibáñez: "El estudio de las especialidades, que tanta influencia ha ejercido en el progreso de las ciencias médicas, por la escasez de población de nuestras ciudades, ha sido poco cultivado entre nosotros. Nuestros médicos se ven obligados, a recetar diariamente, ya un caso de patología interna, ya a practicar una operación, o a prestar los auxilios de la ciencia en un caso de Distocia" (27). Una pintura fiel de la situación en Bogotá la encontramos en la tesis de grado presentada por Enrique Sánchez a la Facultad de Medicina de la Universidad Nacional en 1892: "Fuera de unas pocas aficionadas que sin previos estudios han asistido durante un tiempo insuficiente a las conferencias prácticas dictadas en la maternidad por los eminentes profesores Doctores Leoncio Barreto y José María Buendía, y en donde han aprendido lo más esencial de las atribuciones de las parteras, las demás son mujeres ignorantes llenas de achaques (...)" (28).

En 1870 se radicó en Bogotá, su ciudad de origen, la señorita Ana Galviz Hotz quien había adelantado estudios médicos en París pero se había doctorado en Medicina en Berna, Suiza, con una tesis titulada "Sobre el epitelio del amnios", trabajo éste de mucha importancia (29). En efecto, se trata de una descripción muy cuidadosa y detallada del epitelio amniótico de la placenta humana madura, el cual 
no había sido bien estudiado para la fecha en que la doctora Galvis presentara su tesis. Para entonces se consideraba que el amnios estaba constituido solamente por epitelio pavimentoso. Dando muestras de ser una acuciosa observadora, advierte que sus estudios se refieren, en su mayoría, a preparados conservados artificialmente, y que en algunas oportunidades sus hallazgos fueron comprobados repetidas veces en amnios muy frescos de res y de cerdo, como también de conejillos de Indias recién sacrificados. Describe así sus observaciones: "El amnios maduro lleva en la casi totalidad de su superficie libre un epitelio cilíndrico bien formado. Solamente en la región del polo libre ovular como también a veces, cerca de la placenta, se encuentra epitelio pavimentoso bajo". (30). Además es de admirar que, usando el microscopio de luz, describiera con precisión y se atreviera a asignarles funciones a las columnas o canales intercelulares observados en el amnios, descritos casi cien años después con el microscopio electrónico (31).

Cabe el doble honor a la doctora Ana Galvis de haber sido la primera mujer colombiana graduada en medicina, como también la primera especialista en ginecología. Asimismo, fue ella la primera mujer graduada en una escuela de medicina de Suiza. Por haberse anunciado en Bogotá como "especialista en enfermedades de la mujer", exclusivamente, es de suponer que no incursionó en terrenos obstétricos. No sabemos qué tan buena acogida tuvo entre la sociedad bogotana. Lo cierto es que regresó a Europa pero retornó al país, donde falleció en la capital el 2 de noviembre de 1934. Fueron sus padres el doctor Nicanor Galvis y doña Sofía Hotz.

\section{BIBLIOGRAFIA}

1. Ghalioungui P. La medicina en el Egipto Faraónico. En: Historia Universal de la Medicina, Laín P. Salvat Editores S.A., Barcelona, 1948; p. 47.

2. Leonardo RA. Historia de la Ginecología, Salvat Editores S.A., Barcelona, 1948; p. 47

3. Ibid, p. 60 .

4. Jackson R. Doctors and diseases in the Roman Empire, British Museum Press, London, 1991; p. 87

5. Leonardo. Historia de la Ginecología. p. 135.

6. González JA. Historia de la obstetricia y la ginecología en Guatemala. En: Historia de la Obstetricia y la Ginecología en Latinoamérica. Imprenta Distrital de Bogotá, 1970; p. 229.

7. Castellazo L., Aguilar JA., Calderón J. Historia de la obstetricia y la ginecología en México. En: Historia de la obstetricia y la ginecología en Latinoamérica. Imprenta Distrital de Bogotá, 1970; p. 277.

8. Sánchez-Torres F. "Algunas costumbres ginecobstétricas en la era prehispánica”. Rev. Col. Obst. Gin. 1971; 22: 325.

9. Gutiérrez PA., Archila R. La obstetricia en Venezuela. Editorial Ragón, C.H., Caracas, 1955.

10. Paredes V. Historia de la Medicina en el Ecuador, Ed. Casa de la Cultura Ecuatoriana. Quito, 1963, tomo I, p. 250.

11. Belalcázar JM. Historia de la Medicina en Bolivia. Ediciones Juventud, La Paz, 1956; p. 34.

12. De Urioste FJ. En: Historia de la obstetricia y la ginecología en Latinoamérica, 1970; p. 59.

13. Wood J., Avilés VM. "Historia de la ginecología y la obstetricia en Chile". En: Historia de la Obstetricia y la Ginecología en Latinoamérica. p. 177

14. Usandizaga M. Historia de la Obstetricia en España. Editorial Labor S.A., Barcelona, 1944; p. 109.

15. Ibíd., p. 111.
16. Jackson R. Doctors and diseases..., p. 96.

17. Ledesma DA. Bosquejo histórico de la obstetricia. En: Tratado de Obstetricia, León J., Edit. Científica Argentina, Buenos Aires, tomo III, 1959; p. 1325.

18. Ibíd., p. 1333.

19. Ledesma DA. "Bosquejo histórico..., p. 1334

20. Sánchez-Torres F. La ginecobstetricia en Santafé de Bogotá durante la Conquista y la Colonia. Rev. Col. Obst. Gin. 1972; 23: 359.

21. Rodríguez-Freire J. El Carnero, Imprenta Nacional, Bogotá, 1963; p. 132.

22. Ibáñez PM. Memorias para la historia de la medicina en Santafé de Bogotá, Imprenta de Vapor de Zalamea Hermanos, Bogotá, 1884; p. 77.

23. Mutis JC. En: Documentos sobre el mal estado de la ciencia médica en el Nuevo Reino, No. 169, Libros Raros y Curiosos, Biblioteca Nacional, Bogotá.

24. Ibáñez PM. Memorias para..., p. 77.

25. Sánchez-Torres F. Comentarios histórico-médicos a propósito de una retención de placenta. Rev. Col. Obst. Gin. 1991; 42: 15.

26. Quevedo-Gómez T. Historia de una vocación. Seis generaciones de médicos Quevedo. Conferencia dictada en la Sociedad Colombiana de Historia de la Medicina, Bogotá, septiembre de 1982.

27. Ibáñez PM. Memorias para..., p. 135.

28. Sánchez E. "Necesidad de reglamentar en Colombia el ejercicio de la profesión obstetrical". Tesis de grado, Universidad Nacional, Bogotá, 1892.

29. Ibáñez PM. Memorias para..., p. 135.

30. Galvis-Hotz A. "Uber das Epithel des Amnion". Tesis, Dresden, 1878.

31. Minh HN., Smadja A., Maur PP., Orel L. "Electron microscopic study of intercellular canalicular systems in the parietal fetal membranes". Brit J. Obstet. Gynecol. 1981; 88: 1104. 